\title{
LITERATURA GAUCHESCA Y PARODIA: EL FAUSTO CRIOLLO
}

Nora Pasternac*

RESUMEN: El género gauchesco, la invención más original del Río de la Plata (Uruguay y Argentina), encuentra una de sus cumbres estéticas en el Fausto criollo, de Estanislao del Campo. Por su estructura y motivos, que parten de la obra musical de Gounod, el poema gauchesco ha sobrevivido a todos los avatares culturales y político-ideológicos: un texto asombrosamente moderno, en el que parodia, carnavalización y dialogismo se manifiestan en todo su esplendor, con lenguaje arcaico reelaborado con un género popular deliberado. Las redes intertextuales contribuyen a la perduración del poema.

sose

ABSTRACT: The Gaucho genre, an original creation from Río de la Plata (Uruguay and Argentina), reaches its pinnacle in Estanislao del Campo's Fausto criollo. Due to its structure and purpose originating from Gounod's opera, the Gaucho poem has stood the test of time while confronting cultural and politico- ideological vicissitudes. It is an astounding modern text where parody, carnavalization, and dialogism are shown in all their splendor in a reworked archaic language yet in a deliberate popular genre. The significant intertextuality has contributed to the poem's lasting fame.

PALABRAS CLAVE: literatura gauchesca, Fausto criollo, Estanislao del Campo, cultura popular, tradición, leyenda.

KEY WORDS: Gaucho literature, Fausto criollo, Estanislao del Campo, popular culture, tradition, legend.

RECEPCIÓN: 19 de mayo de 2011.

APROBACIÓN: 11 de octubre de 2011.

* Departamento Académico de Lenguas, ITAM. 
La reproducción total o parcial de este artículo se podrá hacer si el ITAM otorga la autorización previamente por escrito. 


\section{LITERATURA \\ GAUCHESCA Y \\ PARODIA: EL FAUSTO \\ CRIOLLO}

En la ubicua memoria serás mía, Patria, no en la fracción de cada día.

Jorge Luis Borges

La literatura gauchesca, que floreció en ambas orillas del Río de la Plata -el Uruguay y la Argentinaes un fenómeno excepcional en el panorama de las literaturas hispanoamericanas. Comenzó a desarrollarse en forma anónima y por cultores populares, pero terminó transformándose en la expresión de los letrados que la tomaron a su cargo y la desarrollaron hasta convertirla en la expresión de una identidad nacional adoptada como símbolo incluso por los inmigrantes recién llegados, por sus hijos y por sus nietos, en un proceso original de creación de identidad.

Su originalidad está sostenida por diversas características. En primer lugar, no respondió verdaderamente a ningún movimiento estético europeo, por ejemplo el neoclasicismo del siglo XVIII y de comienzos del XIX que imperaba en América Latina. De la misma manera, aunque por algunos rasgos se la pueda emparentar con el Romanticismo, se separa de él por su realismo y por la ausencia de idealización. Excepcionalmente, en lugar de satisfacer las demandas de un público preexistente, terminó en realidad por generarlo; $y$, finalmente, creó completamente una lengua literaria que es su signo más distintivo y su logro más espectacular.

A pesar de su novedad inusitada, la poesía gauchesca no está completamente separada de la evolución de la cultura: incorpora multitud de elementos expresivos de la poesía tradicional española, por ejemplo, 
NORA PASTERNAC

las rondas, las canciones y, sobre todo, las coplas. Del mismo modo, sus temas evocan una especie de adaptación o traducción de los héroes legendarios, los caballeros, los villanos, los reyes y pastores.

A partir de su transmisión oral a través de los payadores, su evolución como género hizo que las manifestaciones cada vez más ilustradas se enriquecieran y engrandecieran hasta convertirse en el género de los autores cultos de las ciudades, hasta alcanzar su cima en el poema nacional por excelencia, el Martín Fierro, de José Hernández, paradigma del gaucho perseguido por las injusticias y las adversidades.

La literatura gauchesca es un género perdurable que, leído hoy, con una continuidad sin desmayos en los estudios literarios hasta el presente, permite redescubrir, con nuevos perfiles críticos e históricos, un gran logro literario. En el caso del Fausto criollo, de Estanislao del Campo, una frescura nunca marchitada, nunca desmentida, junto a la compleja presencia de una verdadera obra de arte.

Jorge Luis Borges y Adolfo Bioy Casares, en el prólogo a los dos tomos de Poesía gauchesca que ellos recopilan y que se publicarían en México en 1955 por el FCE, recuerdan que "en agosto de 1866, Estanislao del Campo asistió a una representación del Fausto de Gounod, en el teatro Colón de Buenos Aires, y pensó en la extrañeza que esa obra produciría en un gaucho; esa misma noche produjo el primer manuscrito de su poema. Éste, como se sabe, registra el diálogo de dos gauchos; uno de ellos, que ha asistido a la representación de la ópera, la refiere a su amigo, como si se tratara de hechos reales". ${ }^{1}$ Inmediatamente, con su malicia habitual, ambos compiladores citan la opinión de Leopoldo Lugones que "censura ese argumento" por inverosímil. Como es de suponerse, Borges y Bioy declaran que aun el arte más naturalista es convencional y que toda la literatura gana con la recurrencia a la "irrealidad": "las convenciones de aceptación más fácil son las que pertenecen al planteo mismo de las obras: $v$. g. 'la ilusión cómica' de Anastasio o la extrema autobiografía rimada de Martín Fierro.” Con lo cual, desdeñan la sobrevaloración nacionalista del Martín Fierro que Lugones siempre propugnó.

1 "Prólogo", Poesía gauchesca, 1955, México, FCE, ed., prólogo, notas y glosario de Jorge Luis Borges y Adolfo Bioy Casares, 2 tomos, p. XV. 
Si bien la emergencia, en su momento más antiguo, del género gauchesco (y en el origen, evidentemente no podía llamarse ni género ni gauchesco) puede considerarse como popular y anónima, ya para la época del gran iniciador y precursor que fue Bartolomé Hidalgo (1788-1822), lo que poco a poco va constituyéndose en género típico del Río de la Plata, corresponde a la definición que Josefina Ludmer resume en lo siguiente: "un uso letrado de la cultura popular". ${ }^{2}$ Todo ocurre en un proceso que culmina, como se señaló más arriba, con el Martín Fierro, el cual, a su vez, clausura la posibilidad de innovar, tal vez para siempre, al mismo tiempo que impone algo así como un rumbo definitivo en la literatura gauchesca, no sólo para el verso, sino también para la prosa, el teatro gauchesco o las narrativas posteriores: Ricardo Gutiérrez, Martiniano Leguizamón, Benito Lynch, o los uruguayos Javier de Viana, Eduardo Acevedo Díaz, Carlos Reyles y tantos otros en ambas márgenes.

Cuando Estanislao del Campo (1834-1880) publica su poema, en 1866, cuyo título completo es Fausto. Impresiones de Anastasio el Pollo en la representación de esa ópera, se integra en la época de mayor brillo del género, junto a Hilario Ascasubi (1807-1875), al uruguayo Antonio Lussich, Los tres gauchos orientales (1872) y, finalmente, a José Hernández, que hace aparecer en un modesto y rústico folleto la primera parte de Martín Fierro en 1872, y la segunda, La vuelta de Martín Fierro, en 1879.

Lo primero que hay que señalar es el evidente homenaje que el autor rinde a Ascasubi: el seudónimo más famoso de Hilario Ascasubi fue "Aniceto el Gallo", y del Campo apoya ese homenaje al hacer un subrayado especial del nombre desde el comienzo, al producirse el encuentro del gaucho con su amigo Laguna:

Cuando el flete relinchó, media güelta dio Laguna y ya pegó el grito: -¡Ahijuna!

¿No es el Pollo? -Pollo, no,

${ }^{2}$ Josefina Ludmer, El género gauchesco. Un tratado sobre la patria, 1988, Buenos Aires, Sudamericana, p. 10. 
ese tiempo se pasó

(contestó el otro paisano);

Yo soy jaca vieja, hermano, con las púas como anzuelo, y a quien ya le niega el suelo hasta el más remoto grano.

Se apió el Pollo y se pegaron tal abrazo con Laguna, que sus dos almas en una acaso se misturaron. Cuando se desenredaron, después de haber lagrimiao, el overito rosao una oreja se rascaba. $(v v .51-68)^{3}$

El éxito del Fausto criollo es arrasador; sin embargo, aunque el público -y muchos intelectuales- lo aceptaron inmediatamente, es conocido que recibió críticas devastadoras (la bibliografía sobre la obra de Estanislao del Campo no debe estar lejos de igualar la dedicada al Martín Fierro): ridiculización del gaucho, visión alejada de una supuesta "verdad" del gaucho. Incluso los críticos se han complacido en señalar las numerosas "inexactitudes" de los detalles; hubo interminables discusiones sobre el ahora famoso "overo rosado", variedad de caballo considerado manso y sólo apto para ser montado por mujeres y nunca "parejero", es decir, caballo de carreras; lo mismo ocurre con el abrazo estrecho de los dos amigos: los gauchos no se abrazan (incluso unos versos de Martín Fierro se refieren críptica y despectivamente a esta escena). ${ }^{4}$

${ }^{3}$ Poesía Gauchesca, pp. 302-303. A partir de aquí, sólo señalaré el número de los versos de esta edición. El Fausto se encuentra entre las páginas 299 y 330. Las ediciones de esta obra son numerosísimas hasta el presente. Su popularidad fue tan grande que, para 1910, fecha del Centenario, se habían publicado ya ciento treinta y seis ediciones. Durante el transcurso del siglo XX se han multiplicado y han dado lugar a todo tipo de versiones y presentaciones, tanto nuevas ediciones eruditas como caricaturas "postmodernas" y cómics.

${ }^{4}$ En un texto canónico sobre el tema y con frases que han sido citadas muchas veces a propósito del desdén hacia el poema, Borges recuerda, de una manera que sitúa al texto en 
Un capítulo aparte merece la crítica, que hoy es constatación de un aspecto agregado, de la "despolitización" de la figura del gaucho en esta versión. Jerónimo Brignone resume, refiriéndose al Fausto:

La progresiva exclusión del gaucho del teatro de operaciones político, pareja a la autonomización del género literario que lo refiere, implicará, en su relegamiento al rol pasivo de espectador, un mayor subrayado de su subjetividad. Ya inútil para el sistema capitalista liberal que se impone hegemónico, comenzará a verse representado a sí mismo en los afeites y adornos, igualmente "inútiles" en términos de producción, con los que la sociedad que lo excluye se engalana: la ópera, la mujer, la flor, sintetizada en el significante "Margarita" del Fausto francés. El demiurgo realizador de dicha representación es el letrado, tanto enemigo como aliado, jugando a Dios disfrazado de Diablo, operador de síntesis y resignificación. ${ }^{5}$

Lo interesante es la cadena metafórica alusiva que se establece a partir de estas consideraciones sobre el lujo, el fasto, lo fausto (la palabra "fausto" merecería una digresión también) de la ocasión, así como la acentuación de los elementos de una subjetividad delicada y sentimental que, aparentemente, debería estar desterrada del género. Sólo unos breves ejemplos de toda la red de paralelismos que pueden establecerse con la ópera. Por un lado, al caballo de Laguna:

\section{le iba sonando al overo \\ la plata que era un primor: \\ pues eran de plata el fiador,}

su verdad estética (que actualmente ha sido recuperada sin que se olviden los costados críticos): "Pasan las circunstancias, pasan los hechos, pasa la erudición de los hombres versados en el pelo de los caballos; lo que no pasa, lo que tal vez será inagotable es el placer que da la contemplación de la felicidad y de la amistad. Ese placer, quizá no menos raro en las letras que en este mundo corporal de nuestros destinos, es en mi opinión la virtud central del poema. [...] Lo esencial es el diálogo, es la clara amistad que trasluce el diálogo. No pertenece el Fausto a la realidad argentina, pertenece -como el tango, como el truco, como Irigoyen- a la mitología argentina." "Poesía gauchesca", Discusión (1932), Obras Completas, 1999, Buenos Aires, EMECÉ, $3^{\mathrm{a}}$ edición, t I, p. 187.

${ }^{5}$ Jerónimo Brignone, "Con Dios y con el Diablo: el Pollo sujeto en la Margarita. Una reflexión sobre el Fausto Criollo", http://www.jbrignone.com.ar/fausto.htlm, publicado en 2002; consultado el 14 de marzo de 2011. 
pretal, espuelas, virolas, y en las cabezadas solas traía el hombre un Potosí: ¡Qué...! ¿Si traía para mí, hasta de plata las bolas! (vv. 23-30).

Por el otro, esta descripción de los lujosos adornos del caballo y del jinete es un anuncio del cofre de joyas de Margarita: "Al ramo no le hizo caso, / enderezó a la cajita, / y sacó... ¡Virgen bendita!.../ ¡viera qué cosa, amigazo!/ ¡Qué anillo! ¡Qué prendedor!/ ¡Qué rosetas soberanas! [...] La rubia allí se colgó / las prendas, y apareció / más platiada que la luna." ( $v v \cdot(785-796)^{6}$

Es decir, la obra de del Campo se presenta como un producto de la autonomización de la obra de arte con respecto a la política y a la guerra (en ese momento, por ejemplo, la del Paraguay). Como dice Josefina Ludmer:

Fausto se constituye por exclusión de lo político. Transforma definitivamente la fiesta política en puramente cultural y cambia así la representación del sistema de relaciones del gaucho con la ciudad, y por lo tanto el vínculo y la alianza de las dos culturas en el género. Los efectos de la despolitización son múltiples: el texto se autonomiza y transforma su relación con la coyuntura, el contexto y el conjunto del sistema de referencias. Aparece por primera vez un poema gauchesco desligado del periodismo, absolutamente "literario", que corta en dos partes el género: Fausto no sólo es un avatar necesario de su historia y consecuencia de su lógica, sino una de las condiciones fundantes de Martín Fierro. ${ }^{7}$

En realidad, se puede hablar con respecto al Fausto criollo, de uno de los avatares de la "refracción de un mito", lo que es uno de los elementos más importantes que fuertemente contribuyó a su éxito y su perduración. La riqueza y la variedad de las versiones de la leyenda

${ }^{6}$ “¡Oh Dios!, ¡cuántas joyas!/ ¿Es un sueño encantador/ que me deslumbra o estoy despierta?/ ¡Mis ojos jamás han visto riqueza semejante!” y el resto de la escena del cofrecillo, libreto de la ópera Fausto, 2007, Madrid, 3 CD, Charles Gounod, Acto Tercero, Colección "Los clásicos de la ópera. 400 años", p. 55.

${ }^{7}$ El género gauchesco, op. cit., p. 253. 
son conocidas: desde comienzos de 1500, con la existencia de un personaje real, alquimista y nigromante, ya registrado por sus contemporáneos como un mago bastante famoso con detalles contradictorios y truculentos, retomado muy pronto por Christopher Marlowe, que compuso su Trágica historia del Doctor Fausto en 1588, pasando por todos los dramas, tratados, por el más célebre y complejo de todos, el de Goethe, marionetas, títeres, músicas, óperas (no olvidar a Wagner, que compuso varias musicalizaciones para el drama de Goethe -en 1839/40 y en 1855- o Héctor Berlioz y su Condenación de Fausto, 1829; o Schumann, Escenas para el Fausto de Goethe, y Liszt, con su Sinfonía Fausto, 1854/57), cada época ha reelaborado este mito germánico convertido en universal. Hay una versión luterana del mito, otra romántica, una iluminista, una positivista, etc. Ya en el siglo XX, entre las más notables se encuentra Mon Faust (1941) de Paul Valéry o L. H. Durrell que escribe An Irish Faust (1939) y, por supuesto, Doktor Faustus (1947), de Thomas Mann, que reflexiona sobre las consecuencias del nazismo, precisamente a partir de la biografía de un músico y compositor, Adrien Leverkühn, relatada por uno de sus amigos. Sólo recordemos que la historia pasó inevitablemente por el cine, por ejemplo, $L a$ belleza del diablo (1950) de René Clair, y numerosísimas otras narraciones fílmicas basadas en la historia del pacto con el Diablo. Son lo que un músico llamaría “variaciones". Por otra parte, la historia de las versiones del Fausto justifica plenamente y sin paradojas la creación del Fausto criollo: en el siglo XIX la historia, en forma de diferentes libretos y obritas, fue el plato fuerte de los teatros de títeres y marionetas en toda Alemania, es decir, se dirigía a un público de ferias, de multitudes campesinas o proletarias y a los niños. Con toda naturalidad, el poema gauchesco se insertaría en la tradición de la leyenda. ${ }^{8}$

${ }^{8}$ Una de las reelaboraciones más logradas es El maestro y Margarita (1966-67, edición completa y definitiva en 1989), del escritor ruso Mijaíl Bulgakov (1891-1940), que constituye una sátira llena de regocijantes bufonadas, osadas alegorías filosóficas y acerada sátira sociopolítica, no sólo del sistema soviético, sino de todo lo que el autor detestaba en la superficialidad y vanidad de la vida moderna en general. La célebre canción "Sympathy for the Devil" de los Rolling Stones (1968) está inspirada a su vez en la novela de Bulgákov. La grabación de la canción también proporciona el tema a la película de Jean-Luc Godard, One plus one (1968); en ella, se realiza un recorrido por la contracultura estadounidense de fines de los sesenta, recorrido mezclado con escenas de los Stones grabando "Sympathy". En suma, la red intertextual es inmensa. 
La ópera de Gounod, en cinco actos, fue representada en París en 1859 y el libreto pertenece a Jules Barbier y Michel Carré. Aunque por mucho tiempo el Fausto de Goethe, en traducción de Gérard de Nerval, fue el libro de cabecera del músico, sería vano buscar una total expresión del contenido poético y metafísico de la gran obra maestra alemana. Gounod desarrolló uno solo de los episodios del poema, los amores de Fausto y Margarita, y en eso creyó ser fiel a su "inclinación apasionada", que le revelaba que el amor es la única condición de la felicidad humana. Esa limitación a un solo sentimiento fuertemente teñido de romanticismo no permitió una traducción musical del poema de Goethe, pero tal vez tampoco constituye una traición. Como la obra de del Campo, tuvo inmediatos detractores y defensores, y aún los tiene modernamente. A su vez, el Fausto criollo minimiza aún más los elementos del mito y los reduce al romance de Fausto con Margarita y a la desdichada suerte final de la muchacha. Sin embargo, hay que decir que, como reflejo de la obra, están muy presentes los elementos de la oposición teológica de Dios-Jesús-la Virgen-el Cielo frente al Diablo-la tentación-el pecado-el crimen-el Infierno. Ante cada aparición de Mefistófeles, Anastasio el Pollo, en su relato (y su oyente hace lo mismo), recurre constantemente a las invocaciones divinas y a la señal de la cruz para exorcizar la presencia del demonio que, en la paródica visión del "rústico", es real. Su descripción corresponde a la representación estereotípica ingenua, pero refuerza la dicotomía entre el Bien y el Mal:

\author{
¡Viera al Diablo! Uñas de gato, \\ flacón, un sable largote, \\ gorro con pluma, capote \\ y una barba de chivato. \\ Medias hasta la verija, \\ Con cada ojo como un charco \\ y cada ceja era un arco \\ para correr la sortija. ( $v v .305-311)$
}


En cambio, Margarita es asimilada a la Virgen:
¡Ah, Don Laguna! ¡Si viera
qué rubia!...Creameló:
creí que estaba viendo yo
alguna virgen de cera.
Vestido azul, medio alzao,
se apareció la muchacha:
pelo de oro, como hilacha
de choclo recién cortao.
Blanca como una cuajada, y celeste la pollera;
don Laguna, si aquello era
mirar a la Inmaculada. (vv. 365-376)

Formalmente, el Fausto criollo está compuesto por 21 décimas y 240 redondillas. La estructura es muy simple. Hay dos campos: un narrador inicial exterior introduce a los personajes, plantea algunos datos para entender el encuentro entre los dos gauchos y cierra, también exteriormente, como en el cine, con el alejamiento de los dos compañeros juntos. Estos dos momentos son breves. En el interior de este marco se desarrolla el diálogo de ambos gauchos, principalmente el relato de la ida al teatro y el argumento de la ópera, tal como el Pollo la entendió, con las réplicas y las intervenciones a veces asombradas, a veces incrédulas de don Laguna. Por otra parte, se ha señalado repetidas veces la conservación de la estructura tradicional de las convenciones gauchescas: el saludo inicial, el convite a la bebida, el tabaco o la comida, conversación sobre los caballos, el tópico de la visita del gaucho a la ciudad y las vicisitudes y engaños a los que se ve sometido. A lo que hay que añadir que, al mismo tiempo, se realiza la invención de un público, la construcción de una lengua y la postulación de una realidad. ${ }^{9}$

${ }^{9}$ Para el desarrollo de estos temas y los anteriores ya mencionados, ver Eduardo Romano, Sobre poesía popular argentina, 1983, Buenos Aires, Centro Editor de América Latina; Ángel Rama, Los gauchipolíticos rioplatenses, 1983, Buenos Aires, Centro Editor de América Latina; Julio Schvartzman, "Las letras del Martín Fierro", en Noé Jitrik (dir.) Historia Crítica de la Literatura Argentina, 2003, Bs.As., Emecé, vol. 2, pp. 225-250. 
Es evidente que esta versión del Fausto evoca inevitablemente las consideraciones de Bajtín sobre la parodia y la carnavalización. La parodia implica que el lector conoce la ópera o, incluso, varias versiones de la historia original, y que, por otra parte, percibe al poema gauchesco como un género. Por otro lado, la parodia implica que haya una compenetración imitativa con el modelo, al mismo tiempo que su distorsión y los dispositivos necesarios para que el lector perciba la asimilación y la discrepancia que producen comicidad.

La carnavalización es muy fuerte en el poema de del Campo. Por ejemplo, la profanación con múltiples variaciones. Desde el comienzo se apunta directamente al derrocamiento de lo "alto", y, al mismo tiempo, curiosamente, las alturas remiten a lo bajo. El Pollo comienza su relato así:

Como a eso de la oración, aura cuatro o cinco noches, vide una fila de coches contra el tiatro Colón.

La gente en el corredor, como hacienda amontonada, pujaba desesperada por llegar al mostrador.

Allí a juerza de sudar, y a punta de hombro y de codo, hice, amigazo, de modo que al fin me pude arrimar.

Cuando compré mi dentrada y di güelta... ¡Cristo mío! estaba pior el gentío que una mar alborotada.

Era a causa de una vieja que le había dao el mal... (Laguna:) Y si es chico ese corral ¿a qué encierran tanta oveja? 
Ahí verá: por fin, cuñao,
a juerza de arrempujón,
salí como mancarrón
que lo sueltan trasijao.

Mis botas nuevas quedaron

lo propio que picadillo, y el fleco del calzoncillo hilo a hilo me sacaron.

Ya para colmo, cuñao, de toda esta desventura, el puñal, de la cintura, me lo habían refalao.

(Laguna:) Algún gringo como la luz para la uña, ha de haber sido. ${ }^{10}$ ¡Y no haberlo yo sentido!

En fin ya le hice la cruz.

Medio cansao y tristón por la pérdida, dentré y una escalera trepé con ciento y un escalón.

Llegué a un alto, finalmente, ande va la paisanada, que era la última camada en la estiba de la gente. (vv. 201-245).

Ya en primera instancia, la idea de parodiar una ópera remite a la oposición entre lo sublime elevado y lo popular folklórico como la gauchesca; un gaucho asistiendo a una ópera es "el mundo al revés", la desviación de la vida de su curso normal. Pero para limitarme sólo al párrafo que he citado, tenemos una muestra. Desde el comienzo de

${ }^{10}$ En esas épocas de constitución de la Nación y de la llegada de los primeros contingentes de inmigrantes, aparece ya la molesta xenofobia de los que al mismo tiempo que habían promovido esa inmigración se sentían "invadidos". Hay que recordar que en la Argentina "gringo" se dice principalmente de los italianos y actualmente con sentido cariñoso. 
NORA PASTERNAC

la cita, el teatro Colón, espacio elegante y frecuentado por la oligarquía, es desacralizado y despojado de su valoración reverente. El vocabulario y las notaciones son camperas, la gente es asimilada al ganado y a los animales -la pampa, el corral, las ovejas. También los atributos gauchos son atacados: los ropajes, la corona, los símbolos de poder, es decir, botas, calzoncillo, cuchillo; el Pollo es empujado y golpeado; transpira abundantemente. Todo ello recuerda, por supuesto, el concepto de "doble destronamiento" bajtiniano. ${ }^{11}$

Lo alto y lo bajo son evocados directamente: el gaucho debe subir "ciento y un" escalón, hasta el "paraíso" como se le llama a la sección de las entradas más económicas, donde se encuentra la "paisanada que era la última camada en la estiba de la gente." Se insinúa la presencia del bien y del mal, dicotomía de la ópera: Cristo, en la exclamación e invocación, y el robo del cuchillo por un diabólico y supuesto "gringo" a quien se le hace "la cruz", que es también la de la empuñadura del facón, y que recuerda la presentación de la "cruz" de las espadas de los jóvenes de la taberna en la ópera cuando descubren la presencia del diablo.

Por su parte, Josefina Ludmer señala algunas consecuencias más sutiles o, en todo caso, más ligadas históricamente al género gauchesco, con respecto a la parodia:

El texto opera entonces sobre los dos polos del género y las dos culturas. Cada parte sostenida por un narrador es contada desde la modalidad, el modo de representación y la creencia que corresponde a la otra cultura. [...] el punto donde puede construirse la alianza es que las dos son, por así decirlo, mixtas: el género gauchesco, escritura de lo oral, hecho del abrazo de la cultura popular y la letrada, y la ópera, texto letrado en versión oral, canto fundado en lo escrito, literatura oralizada hecha sobre un texto culto construido a su vez sobre una leyenda popular oral. [...] El diálogo de las dos culturas se realiza en Fausto entre el género gauchesco y la poesía culta; las dos se encuentran y se parodian entre sí:

${ }^{11}$ Estas observaciones y algunas de las que siguen resumen un excelente estudio con respecto a estos temas: Antonio Carreño-Rodríguez, "Modernidad en la literatura gauchesca: el Fausto de Estanislao del Campo”, Hispania, marzo de 2009, vol. 92, núm. 1, pp. 12-24. 
la lectura produce risa por el contacto y biasociación de dos modelizaciones aparentemente incompatibles. Pero la parodia se inscribe en una concepción de la literatura como sistema autónomo [...] La parodia representa entonces un conflicto puramente cultural. ${ }^{12}$

Por esas razones, la sentimentalidad puede desplegarse en lo que concierne al amor y al personaje femenino. En la literatura gauchesca, en general, las mujeres pertenecen al pasado feliz del gaucho y no tienen presencia ni descripción, o son la conquista de un momento, casi siempre casquivanas o estereotipadas. Es la inmediata reacción de Laguna cuando el Pollo hace la apología del amor:

Y digo pobre dotor, porque pienso, don Laguna, que no hay desgracia ninguna como un desdichado amor.

-Puede ser; pero amigazo, yo en las cuartas no me enriedo, $\mathrm{y}$ en un lance en que no puedo, hago de mi alma un cedazo.

Por hembras yo no me pierdo: la que me empaca su amor pasa por el cernidor y... si te vi, no me acuerdo.

Lo demás es calentarse... el mate al divino ñudo... -¡Feliz quien tenga ese escudo con que poder rejuardarse!

Pero usté habla, don Laguna, como un hombre que ha vivido sin haber nunca querido con alma y vida a ninguna.

${ }^{12}$ El género gauchesco..., pp. 259-60. El subrayado es de la autora. 


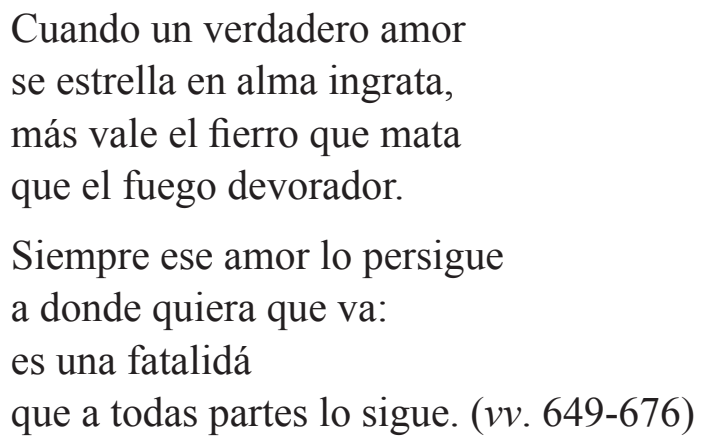

Y el canto al amor desdichado sigue largamente lleno de imágenes y metáforas que juegan con la obsesión amorosa. Al mismo tiempo, cuando el Pollo se conmueve con la suerte de Margarita, asoma de manera insólita una defensa compasiva de la situación femenina. Se presenta como una comparación entre las fechorías finalmente perdonadas y hasta festejadas del gaucho y la condena de las infelices muchachas engañadas.

Cuando a usté un hombre lo ofiende, ya sin mirar para atrás, pela el flamenco y ¡zas! ¡tras! dos puñaladas le priende. [...]

Pasa el tiempo, vuelve al pago, y cuanto más larga ha sido su ausiencia, usté es recebido con más gusto y más halago. [...]

Engaña usté a una infeliz[...]

Pero sola y despreciada en el mundo ¿qué ha de hacer? ¿A quién la cara volver? ¿Ánde llevar la pisada? 
Soltar al aire su queja

será su solo consuelo, y empapar con llanto el pelo del hijo que usted le deja.

Pues ese dolor profundo a la rubia la secaba. (vv. 921-962)

Inevitablemente, se debe recordar el extenso análisis que Marshall Berman ${ }^{13}$ le dedica al Fausto de Goethe, porque de algún modo es una apostilla a las características de esta visión compasiva, insólita para la poesía gauchesca, pero que en realidad, forma parte de la representación artística autónoma y de la modernización de las posibilidades del género gauchesco que se atreve a introducir nuevas visiones de lo gauchesco. Para Berman, la versión de Goethe del tema del Fausto corresponde a la aparición de un sistema mundial "característicamente moderno" y Fausto posee un impulso vital que llama "el deseo de desarrollo", y es el propio Berman el que subraya la palabra. Para resumir de manera esquemática el rico análisis del crítico, ese desarrollo tiene que ver con el autodesarrollo en el seno de la modernidad, ligado a una transformación total del mundo físico, social y moral en el que se vive. En cambio, Margarita pertenece al orden antiguo, medieval, de las pobres gentes encerradas en una aldea en la que la "caída" en el pecado de una joven es vigilada y condenada por la comunidad patriarcal y hasta medieval en la que vive con las apariencias de un mundo idílico y extremadamente simple. "Su relación amorosa dramatizará el impacto trágico -simultáneamente explosivo e implosivode los deseos y sensibilidades modernos en un mundo patriarcal", dice Berman. ${ }^{14}$ Los habitantes del pequeño mundo, "ese mundo de total contento" que la rodea, la rechazan, la condenan; su hermano muere maldiciéndola; ella enloquece por la culpa. "Con Fausto ausente, Margarita está totalmente desprotegida -en un mundo todavía feudal donde no sólo la posición social sino la supervivencia dependen de per-

13 "El Fausto de Goethe: la tragedia del desarrollo", Todo lo sólido se desvanece en el aire. La experiencia de la modernidad, 1988, Madrid, Siglo XXI, pp. 28-80.

${ }^{14}$ Ibidem, p. 43. 
sonas más poderosas (Fausto, por supuesto, ha tenido todo el tiempo una excelente protección)". ${ }^{15}$ De todos modos, su trayectoria estaba destinada a acabar en desastre por evidentes razones de sexo y de clase. En la ópera, esta contraposición es más clara que en el poema gauchesco, pero en este último está también fuertemente subrayada cuando el Pollo recuerda algo que, para los lectores del siglo XIX y para los del XX, debía ser muy familiar, aunque no cuestionado, y que representa un recuerdo de la modernidad que, lentamente, avanzaba aun en los confines de la pampa legendaria: "Si ella tuviese un hermano, / y en su rancho miserable / hubiera colgado un sable, / juera otra cosa paisano." (vv. 952-956) En suma, como recuerda Marshall Berman, y lo que dice es algo que probablemente también se aplica a una parte del mundo añorado del gaucho: "Este retrato [el de una Gesellschaft] debería grabar para siempre en nuestras mentes la crueldad y brutalidad de tantas formas de vida barridas por la modernización. Mientras recordemos la suerte corrida por Margarita, seremos inmunes a la añoranza nostálgica de los mundos perdidos." 16

Para terminar, es evidente que la gracia que ha conservado el Fausto criollo se debe justamente a esta sofistificación precursora del arte dentro del arte, del relato independiente -la autonomía de la obra literaria- que prefigura a la literatura de la modernidad. Indudablemente, el Fausto anuncia la literatura por venir. El poema es un diálogo y al mismo tiempo responde, por adelantado, a las proposiciones de Bajtín sobre lo dialógico y lo polifónico de la construcción de la novela o la narración moderna con su presentación compleja de varios puntos de vista y la puesta en duda de todo enunciado.

15 "Está destinada a encontrarse a merced de unos hombres que no tienen compasión hacia una mujer que no sabe cuál es su lugar. En su mundo cerrado, tal vez los únicos lugares a donde pueda ir sean la locura y el martirio", ibidem, p. 48.

${ }^{16}$ Ibidem, p. 50. 